\title{
SILENCIAMENTO E DIÁLOGO NA AVALIAÇÃO ESCOLAR
}

\author{
Maria Teresa Esteban \\ Bruna de Souza Fabricante Pina
}

\begin{abstract}
Resumo
Os movimentos cotidianos de produção da educação como prática da liberdade em escolas públicas levam à problematização do ato pedagógico. Neste contexto, o artigo trata dos sentidos assumidos pela avaliação nas práticas escolares e suas conexões com a intensificação da dimensão democrática da escola pública, compreendendo seus vínculos com os projetos de educação e de sociedade em disputa. A pesquisa com o cotidiano escolar se valeu do diálogo como método e do paradigma indiciário para entrar em relação com professoras, crianças e documentos. O pensamento freireano e estudos decoloniais, pós-coloniais e sobre avaliação educacional ofereceram delineamentos que permitiram a interpelação da avaliação escolar, dando a ver propostas que silenciam e suas fissuras, possibilidades de ruptura com o instituído e a presença de inquietações e fluxos dialógicos.
\end{abstract}

Palavras-chave: avaliação; cotidiano escolar; educação libertadora.

\section{SILENCE AND DIALOGUE IN SCHOOL ASSESSMENT}

\begin{abstract}
The daily movements of production of education as a practice of freedom in public schools lead to the problematization of the pedagogical act. In this context, this article deals with the meanings assumed by the evaluation in school practices and their connections with the intensification of the public school's democratic dimension, understanding its relation with the projects of education and society in dispute. The research with the school daily life used the dialogue as a method and the evidential paradigm to enter into relationship with teachers, children and documents. Freire's thought, the decolonial and post-colonial studies, together with those on educational evaluation offered outlines that allowed the interpellation of school assessment, showing proposals that silence and their fissures, possibilities of rupture with the instituted and the presence of restlessness and dialogical flows.
\end{abstract}

Keywords: assessment; school daily life; liberating education.

\section{SILENCIAMIENTO Y DIÁLOGO EN LA EVALUACIÓN ESCOLAR}

\section{Resumen}

Los movimientos cotidianos de producción de la educación como práctica de libertad en escuelas públicas llevan a problematizar el acto pedagógico. En este contexto, el artículo trata de los sentidos que la evaluación en las prácticas escolares asume y sus conexiones con la intensificación de la dimensión democrática de la escuela pública, percibiendo sus vínculos con proyectos de educación y de sociedad en disputa. La investigación con el cotidiano escolar se valió del diálogo como método y del paradigma indiciario para entrar en relación con maestras, niños/as y documentos. El pensamiento freiriano y estudios decoloniales, poscoloniales y sobre evaluación educacional han ofrecido la delineación que nos permitió interpelar la evaluación escolar, dejando ver propuestas que silencian y sus grietas, posibilidades de ruptura con lo instituido y la presencia de inquietudes y flujos dialógicos.

Palabras clave: evaluación; cotidiano escolar; educación liberadora. 


\section{SILENCIAMENTO E DIÁLOGO NA AVALIAÇÃO ESCOLAR}

Em tempos de intenso retrocesso no processo de democratização da sociedade brasileira, como o que estamos vivendo, é preciso reforçar o cuidado com as práticas escolares cotidianas, no sentido de garantir seus vínculos com a conquista e manutenção do direito à educação em uma escola pública de qualidade socialmente referenciada.

Uma escola que afirme a educação como prática da liberdade, como proposta por Freire.

A avaliação escolar é relevante na produção cotidiana dessa escola. Porém, é preciso lembrar que nem toda prática avaliativa pode contribuir com esse projeto de escolarização. A avaliação educacional ou escolar, como uma das configurações da avaliação como prática social, se enreda nas tensões, contradições e lutas da sociedade, de modo que ao integrar-se ao conjunto de processos realizados na escola produz-se como um importante elo entre a escola e a sociedade. No âmbito da escolarização, no entanto, adquire especificidades. Em sua composição cotidiana se entrelaçam as dimensões pedagógica, histórica, cultural, social, política e epistemológica presentes na formulação de qualquer processo educacional. A proposta de avaliação encaminhada na escola está demarcada por projetos de educação e de sociedade, embora nem sempre essa relação seja observada.

Neste artigo, a referência está na avaliação como processo inscrito na relação aprendizagemensino que se articula pela dimensão democrática da educação escolar e se entrelaça às experiências da sala de aula, observando suas vinculações escolar e social ${ }^{1}$. Entrando na escola, com a realização de uma pesquisa com o cotidiano da escola pública, mais uma vez recorro a Freire para reiterar que, como todo ato pedagógico, a avaliação é um ato político. Reconhecê-la deste modo implica na afirmação dos vínculos entre a avaliação que praticamos e o projeto de educação a que nos filiamos, relacionado a nossos modos de ser, compreender e estar no mundo. Logo, a ação não responde estritamente ao projeto instituído, mas ao que produzimos cotidianamente nessa relação.

\section{O NÃO VISTO, O SILENCIADO E O DESIGUAL COMO INDÍCIOS DOS LIMITES DA CLASSIFICAÇÃO}

O papel desempenhado pela mensuração e pela classificação na avaliação escolar é uma questão que atravessa os debates sobre esse tema. É recorrente a afirmação da primazia da sua dimensão qualitativa, contudo, no modelo hegemônico de avaliação mantém-se o predomínio de aferição do desempenho e classificação hierárquica das/os estudantes, alheias à complexidade das aprendizagens e às múltiplas dimensões que constituem a escolarização (HOFFMANN, 2005). Transformá-lo, questão há tempo tematizada no âmbito dos estudos sobre avaliação (FRANCO, 1990; GUBA; LINCOLN, 1989; GIMENO SACRISTÁN, 1982), demanda intensificar a problematização dos procedimentos que fortalecem os vínculos entre a avaliação escolar, exclusão e redução da autonomia dos sujeitos e da alteridade.

\footnotetext{
${ }^{1}$ Segundo a nossa percepção, essa concepção do processo avaliativo está nos marcos da quarta geração de avaliação, segundo organização das perspectivas desenvolvidas no campo da avaliação, proposta por Guba e Lincoln (1989). Os autores identificam um processo de evolução conceitual que desemboca no que denominam avaliação responsiva, caracterizada pelo reconhecimento da presença de aspectos políticos, sociais, culturais e éticos, no processo de avaliação, e pela possibilidade de crítica e de reconstrução. As propostas metodológicas são flexíveis, envolvendo todos os sujeitos que participam da relação.
} 
A avaliação, como se sabe, não se limita à constatação: ela interroga, desafia, conecta e propõe. Contudo, cada uma dessas ações pode adquirir significados vários, segundo o contexto em que se efetivam, o que confere à prática avaliativa papéis distintos no processo de escolarização com as tantas nuances que se produzem entre as óticas conservadora e transformadora da dinâmica pedagógica.

A condução da minha argumentação se ampara no projeto de educação libertadora, na qual a escolarização se articula a uma pedagogia do oprimido, ancorada, evidentemente, no pensamento freireano. Nele ressalto a noção de problematização, que assumida pelo ato avaliativo lhe confere maior densidade e o enlaça às demandas das classes populares: "a existência humana é, porque se faz perguntando, a raiz da transformação do mundo. Há uma radicalidade na existência, que é a radicalidade do ato de perguntar." (FREIRE; FAUNDEZ, 1985, p. 51)

A possibilidade de produção de diferentes práticas sociais e políticas, indispensável ao conhecimento do mundo e ao processo de libertação, se articula à problematização. Problematizar exige perguntar, perguntar-se. Avaliar, também.

No contexto dessa problematização, integrada à interpelação do modelo de avaliação classificatória que afirma, define, circunscreve e institui, limitando o espaço para a pergunta - sobre o processo e no próprio processo -, se articulou a pesquisa que sustenta este artigo ${ }^{2}$. Realizada em 4 municípios fluminenses, envolveu 6 escolas públicas e tratou das implicações da Provinha Brasil na organização do processo de alfabetização, levando a um aprofundamento da percepção da composição dos processos de avaliação no cotidiano escolar e suas tensões. Caracterizada como uma pesquisa com o cotidiano (ALVES, 2001; GARCIA, 2003), portanto de natureza qualitativa, assumiu o diálogo como método (FREIRE, 2006) e se valeu do paradigma indiciário (GINZBURG, 1991) como instrumento conceitual para a leitura dos dados produzidos também por resquícios, pedaços e fraturas e para a elaboração do que se entrevê ou se intui no que se torna opaco, é silenciado ou tornado inexistente ou ausente, movimentos necessários à produção de significações para o que se encontra na investigação. O trabalho envolveu análise de documentos, acompanhamento de turmas em processo de alfabetização, coleta de produções infantis, produção de atividades e conversas com as professoras e as crianças, além da parceria com profissionais atuando nas Secretarias Municipais de Educação participantes da pesquisa.

O estudo indica que a interrogação sobre o modelo hegemônico, suas partes, etapas e relações; sobre as conexões entre as dinâmicas extra e intraescolares; sobre o que cotidianamente se realiza, para além do prescrito e do habitual e sobre os contextos em que se inscreve a avaliação, integra-se ao movimento de transformação assinalado pela abordagem teórica e por ações escolares. Visando não só ao processo avaliativo classificatório, mas também às dinâmicas pedagógicas atravessadas pela ótica da seleção, das quais a avaliação vem sendo um dos relevantes articuladores.

A crítica a essa perspectiva de avaliação, contudo, não impede o reconhecimento de que ela instaura, tanto em sua modalidade externa quanto interna à escola, procedimentos e percepções competentes para a constatação da desigualdade nos resultados escolares, dando visibilidade à permanência de um grave e histórico problema. Porém, nossa pesquisa, ao acompanhar práticas avaliativas no cotidiano escolar, evidencia a frequente descontextualização de critérios que sustentam esse processo, de dados que nele se produzem e de explicações que a partir deles se elaboram, resultando em conclusões pouco significativas para muitos dos sujeitos submetidos à

${ }^{2}$ Em suas diferentes etapas, a pesquisa contou com apoio da FAPERJ e do CNPq. 
avaliação. A uniformização dos processos, a centralização na elaboração de instrumentos e a padronização/quantificação dos resultados orientam e justificam a classificação de estudantes, mas se mostram ineficazes para dar visibilidade às diferentes aprendizagens realizadas, as suas conexões com as propostas de ensino e com o contexto social e aos modos de organização do trabalho na escola.

Nesse sentido, a avaliação estruturada sob a ótica da homogeneidade se mostra insuficiente para sustentar a compreensão mais consistente dos processos escolares e a formulação de propostas e decisões efetivamente vinculadas aos movimentos estabelecidos na relação aprendizagemensino, aos sujeitos que estão na escola e às questões que a ela trazem. Voltada ao padrão, ao que se deve alcançar, a avaliação nem sempre vê a criança em sua complexidade e suas tantas aprendizagens, tampouco reconhece seus saberes e seus modo de conhecer. A permanência da desigualdade de resultados, comprovada pela avaliação classificatória - como prática escolar ou como processo externo em larga escala -, oferece fortes indícios de que os procedimentos postos em marcha não desestruturam a dimensão excludente que também se faz presente na escolarização.

A pedagogia pautada na uniformização de resultados, qualificados segundo parâmetros dissociados dos cotidianos escolares onde se configuram, se aproxima dos movimentos de exclusão. A produção do ensino vai se afastando da sala de aula, da escola e mesmo das aprendizagens; se desconectando do projeto político pedagógico de cada unidade, como articulador de um projeto da comunidade. A escuta do discurso oficial ${ }^{3}$, o acompanhamento de processos escolares e a conversa com professoras atuando nos anos iniciais do Ensino Fundamental, no âmbito da nossa pesquisa, expõem a avaliação externa estandardizada como mecanismo de validação e legitimação da aprendizagem e do ensino. A avaliação em larga escala, ao introduzir na escola uma definição extrínseca e uniforme de padrões desejáveis de aprendizagem (associada a desempenho no teste), mobiliza o ensino no sentido de ajustar - mesmo que restringindo - as ações e as aprendizagens dos/as estudantes ao estândar. Como efeito, induz à restrição dos conhecimentos escolares àqueles conteúdos e modos de expressá-los incorporados ao teste, bem como à valorização de atividades descontextualizadas, baseadas no treinamento e na reprodução do que foi ensinado, em detrimento dos processos reflexivos e críticos e da potência dialógica e criativa da sala de aula. A homogeneidade de parâmetros e de resultados válidos produz recortes que desarticulam a avaliação (assumida como aferição de desempenho estudantil) dos processos pedagógicos, de modo que ensino e aprendizagem são apartados e a dinâmica coletiva da sala de aula e da escola é, de certa forma, destituída de relevância ${ }^{4}$.

A dissociação entre o ensino pautado pelos padrões de qualidade predefinidos e as demandas de aprendizagem evidenciadas na sala de aula também se explicita na constatação de que a avaliação classificatória amplifica os mecanismos de controle externo do trabalho docente no que se refere ao conteúdo a ser ensinado e ao modo de fazê-lo, sem necessariamente gerar mais

\footnotetext{
${ }^{3}$ Trato como discurso oficial os documentos produzidos pelo Ministério de Educação e por Secretarias de Educação sobre avaliação e sobre os processos pedagógicos e orientações e normas que chegam a escola de um modo mais informal, como avisos em reuniões de professores e professoras, indicações dadas por profissionais da equipe técnicopedagógica das escolas, informações repassadas por professores e professoras a partir de cursos realizados no âmbito dos processos institucionais de formação, entre outros.

${ }^{4}$ Pesquisa realizada com profissionais da educação em escolas públicas municipais indica que as avaliações em larga escala não captam dimensões e ações que, segundo eles e elas, expressam e/ou influenciam a produção da qualidade social da escola. Destacam a ausência de indicadores voltados a elementos sócio comunitários, a relações educativas intersubjetivas, à formação, à organização coletiva do trabalho escolar e às condições objetivas de trabalho, entre outros. (TOMAZ; SILVA, 2017)
} 
aprendizagem, mesmo quando leva ao aumento no desempenho. Conclusão semelhante à encontrada por outros trabalhos (HORTA NETO, 2014; VILLASBOAS; DIAS, 2015) em convergência com estudos anteriores que anunciavam a redução da autonomia como inerente ao modelo implementado (APPLE, 1996; FREITAS, 2012).

Há uma crescente atuação sobre a docência que resulta na progressiva mudança da proposição do/a professor/a como intelectual crítico/a e transformador/a para vê-lo/a como técnico/a que aplica em sala de aula o que se determina e se produz em outras instâncias, como há bastante tempo se sabe (GIROUX, 1987). Nesse contexto, é inevitável a redução da autonomia docente, posto que o ensino se confunde com a utilização de práticas mecanicistas (ZEICHNER, 2002) constantemente relacionadas à redução do currículo (ARROYO, 2017; FREITAS, 2007). As ideias de objetividade e neutralidade que se projetam nessa pedagogia do exame (DÍAZ BARRIGA, 1999), percebida como técnica e universal, fazem de seus resultados justificativas confiáveis para a hierarquização dos/as estudantes e para seus percursos escolares desiguais.

Os necessários vínculos entre avaliação escolar e processos socioculturais indicam que sua constituição dentro de um modelo classificatório só tem sentido como parte de um projeto de sociedade em que a escolarização sintoniza com a produção da desigualdade que o caracteriza (FREITAS, 2012). Com os ajustes requeridos para sua adequação ao programa neoliberal, a escola mantém-se enraizada na perspectiva moderna, atualizando a ambivalência (BHABHA, 1989) de sua proposta democrática: suas conexões com movimentos de emancipação são simultâneas à produção de dispositivos sociais de controle, de normalização e de ordenamento (FOUCAULT, 1999). Fundada em uma lógica eurocêntrica, a escola reveste-se de caráter monocultural por reconhecer como conhecimento válido exclusivamente o que deriva do pensamento ocidental ${ }^{5}$. Sendo essa a concepção dominante, a diferença que se encontra no cotidiano escolar - expressão de uma sociedade indiscutivelmente pluricultural - frequentemente se traduz em desigualdade.

A noção de diferença colonial proposta por Mignolo (2003) nos ajuda a perceber o enquadramento macroestrutural da relação entre classificação, avaliação educacional e produção de desigualdade escolar. Para o autor, o imaginário moderno/colonial institui uma classificação do planeta em que subalternização do conhecimento e subjugação dos povos se conjugam na prática da colonialidade do poder ${ }^{6}$ de modo a transformar diferenças em valores desiguais. Nessa perspectiva, o projeto de escola universalizado se liga às estratégias civilizadoras do projeto moderno colonial que produzem o Outro como negação e incapacidade. Sua dinâmica, no âmbito do pensamento hegemônico, se vincula à manutenção de processos de subordinação indispensáveis à ordem global vigente.

Há, portanto, concepções teórico-epistemológicas que explicam a diferença como expressão da falta e como fator de produção da desigualdade, às quais também se articulam projetos educacionais e processos escolares. Nelas se ampara o caráter regulador da educação antidialógica (FREIRE, 2006), que atua de modo a normatizar os processos cotidianos e normalizar os sujeitos. Regulação, controle e normatização conectam tal perspectiva às que configuram a política de

\footnotetext{
${ }^{5}$ Sobre o papel dos organismos multilaterais na imposição da epistemologia eurocêntrica aos países do sul global, tendo os testes estandardizados como um de seus importantes veículos, ver Afonso (2017).

${ }^{6}$ Os estudos decoloniais latino-americanos produzem a noção de colonialidade para tratar das relações de colonialismo que persistem como relação social após o fim do período colonial como relação política. Definem três formas de colonialidade - do poder, do saber e do ser -, incorporadas a novos projetos globais, consoantes à hegemonia, também epistemológica. A colonialidade do poder se refere à distribuição, dominação e exploração do trabalho segundo hierarquias étnico-raciais produzidas na modernidade.
} 
avaliação corrente, cujas propostas se fundam predominantemente na prescrição no que se refere à avaliação externa e permanecem marcadas pela ótica prescritiva, ainda que com maior fluidez e tensão, no cotidiano escolar.

Para Freire (2006, p.37): “Um dos elementos básicos da mediação opressores-oprimidos é a prescrição. Toda prescrição é a imposição da opção de uma consciência a outra. Daí o sentido alienador das prescrições."

Assim, o discurso pedagógico encontra diversas concepções que sustentam a natureza excludente da avaliação classificatória. Nos modelos atuais de avaliação podemos considerar como sua expressão o predomínio do exame, constituído a partir de um padrão composto por um conjunto de questões que pretendem ter um discurso unívoco, configurado, que está, nos marcos da cultura que se reconhece como universal, ao qual deve se ajustar a multiplicidade de conhecimentos, de culturas e de processos de aprendizagem. Em decorrência de sua qualidade técnica, o exame é apresentado como um procedimento adequado à mensuração do desempenho, considerado como espelho da aprendizagem, e seus resultados se apresentam como uma base confiável para prescrições.

Esse processo se entrelaça aos tantos outros processos sociais de negação da alteridade, de recusa da pluralidade cultural e de apagamento das possibilidades de formulação e enunciação da contrapalavra, consoantes às demandas da colonialidade. Ao definir um centro e torná-lo referência de validez e qualidade, o projeto moderno-colonial desqualifica e torna periféricas todas as culturas que diferem da hegemônica. A deslegitimação dos saberes das classes populares expressa a desvalorização de seus processos de produção de conhecimento, destitui de validez seus modos de produzir a vida - marcados por negações, lutas e criação - e articula práticas pedagógicas aos processos sociais de produção e manutenção da subalternidade.

Nos atos escolares marcados pela subalternização, a prescrição e o desempenho se encontram e dão legitimidade à negação da diferença, que sob o discurso da igualdade de oportunidades adquire uma feição democrática. Uma avaliação que se elabora em torno de pontos de chegada, objetivos ou metas pré-fixados e uniformes a se alcançar toma a homogeneidade como sua principal referência e se volta à promoção da individualização dos processos e resultados. A proposta do mesmo para todos, afirmada como democrática, oculta ser uma opção que resulta na criação de obstáculos para estudantes que não correspondem aos modelos social e culturalmente valorizados (APPLE, 1996). A classificação decorre de uma escala em que a hierarquia expressa os valores desiguais atribuídos aos diferentes desempenhos estudantis, estreitamente relacionados também à diferença cultural ${ }^{7}$, cujo matiz discriminador nos ajuda a desfiar as tramas em que se entretecem os processos extra e intraescolar de produção de iniquidade.

Acompanhando turmas em processo de alfabetização encontramos, amiúde, atividades descontextualizadas, voltadas ao treinamento de habilidades e procedimentos de codificação e decodificação, pouco (ou nada) relacionadas a leitura e escrita como processos discursivos, que alimentam movimentos dialógicos. Exercícios que reproduziam questões presentes nos testes estandardizados aplicados às crianças. Prática docente algumas vezes orientada por setores pedagógicos da própria escola ou da Secretaria Municipal de Educação, com a intenção de garantir bons desempenhos nas avaliações.

\footnotetext{
${ }^{7}$ Refiro-me a diferença cultural como proposta por Bhabha(1989, p. 63): “[...] um processo de significação através do qual afirmações da cultura ou sobre a cultura diferenciam, discriminam e autorizam a produção de um campo de força, referência, aplicabilidade e capacidade".
} 
Não é incomum, inclusive, que se alcancem os esperados resultados positivos. Sem embargo, o diálogo com professoras e estudantes nas escolas indica que a conclusão do ciclo de alfabetização não vem sendo garantia de inserção na cultura escrita e de apropriação dessa linguagem para dizer a sua palavra desde seu próprio lugar de enunciação. A experiência escolar expõe a possibilidade de que os resultados na avaliação classificatória nem sempre correspondam à aprendizagem realizada. A tendência desses processos é a amplificação da desigualdade, mesmo quando se escolariza a todos ou a quase todos.

Os processos cotidianos, os desafios da sala de aula, os encontros entre docentes e discentes indicam que o modelo de avaliação hegemônico, articulado pela lógica monocultural e constituído por prescrições, não responde satisfatoriamente às demandas que a sociedade pluricultural faz a uma escola pública que se pretenda democrática ${ }^{8}$. Uma vez que ao tratar a diferença (característica da vida humana) como evidência de impossibilidade e justificativa para a desigualdade (esta, uma produção social) atua inevitavelmente para a consolidação, no cotidiano escolar, de práticas discriminatórias, que estigmatizam sujeitos, conhecimentos, processos e resultados, e naturalizam os movimentos de exclusão.

A avaliação classificatória é um dos dispositivos escolares que silencia a diferença e contribui para ofuscar o processo de silenciamento. Não é demais lembrar que a avaliação escolar costuma ser congruente com os valores socioculturais, o que a inscreve num espaço de disputa.

\section{CUMPLICIDADE, RUPTURAS E MOVIMENTOS DIALÓGICOS}

Em um país como o Brasil, caracterizado por multiplicidade cultural e desigualdade socioeconômica, a avaliação classificatória pode ser compreendida como componente dos dispositivos sociais de intensificação da desigualdade e de redução da presença das diferentes culturas aqui existentes, na formulação do projeto de sociedade. A legitimidade de uma classificação que hierarquiza sujeitos, conhecimentos e processos contribui para dar certa opacidade à diferença cultural (BHABHA, 1989) no processo educacional e para naturalizar a distinção entre quem aprende (alcança bom desempenho) e que apresenta dificuldade de aprendizagem (como constantemente documentos oficiais e falas cotidianas denominam quem não atinge os resultados esperados). Sendo estes últimos frequentemente pertencentes às classes populares. Essa dinâmica escolar permite uma gestão das diferenças e das desigualdades sem demandar uma efetiva problematização das aprendizagens, dos conhecimentos, dos processos pedagógicos, dos parâmetros instituídos e sobretudo do abismo que fratura a sociedade brasileira, em virtude da desigualdade socioeconômica que segue pouco alterada' .

Não quero afirmar, com essa observação, que a desigualdade social resulta da ação escolar, ou que a escolarização possa eliminá-la. Entretanto, considero imperativa a reflexão profunda e coletiva sobre a responsabilidade da escola em relação aos processos sociais de produção e manutenção da desigualdade. Entendo ser necessário interpelar os valores e a concepção de

\footnotetext{
8 A esse respeito ver Walsh (2009).

${ }^{9}$ A respeito do crescimento da desigualdade socioeconômica no mundo, ver: ALSTON, Philip. The parlous state of poverty eradication. Report of the Special Rapporteur on extreme poverty and human rights. Disponível em https://chrgj.org/wp-content/uploads/2020/07/Alston-Poverty-Report

FINAL.pdf?fbclid=IwAR2aXfPzqKcFKJrZo28RGM3es7MN6jDvbbcHTKFvC9qf4QRLfidBE-Hv-eM. Acesso em 10 jul. 2020.
} 
sociedade que sustentam as práticas escolares cotidianas em que se busca enclausurar o conhecimento e também as relações intersubjetivas que constituem o trabalho pedagógico.

É preciso problematizar a afirmação da escola como projeto democrático, como se este fosse um conceito unívoco. Quando não se considera a dimensão de subalternização que também a constitui, ignora-se a produção de um intrincado conjunto de movimentos de visibilidade e invisibilidade dos sujeitos (docentes e discentes), seus processos e seus conhecimentos e aprendizagens, que contribui para a ocultação da exclusão como um dos fios significativos na produção da meritocracia, assumida no projeto hegemônico como justa. A defesa da universalização da escola nem sempre advém da validação dos diferentes, com suas diferenças. Por vezes, a escola lhes destina um lugar subalterno: o dos/as que não aprendem ${ }^{10}$. Tal compreensão salienta a permanência da dimensão normalizadora da ação escolar, que requer da avaliação processos de controle hierárquico e de coerção.

Ao trazer essas possibilidades, ressalto a escola pública como espaço de tensão, luta e disputa de projetos de educação. Portanto, espaço de exercício da democracia. O cotidiano escolar não comporta práticas unívocas e unidirecionais, pois se constitui pela diferença, ainda que quase sempre algumas ideias predominem na condução dos processos. Penso ser indispensável problematizar os sentidos dos projetos educacionais, observando o quanto são portadores de uma perspectiva excludente de sociedade. Igualmente importante é ressaltar os movimentos que os conectam aos discursos de transformação e de libertação.

Para tratar da dimensão de transformação existente na escola, retomo a proposição de Mignolo (2003) sobre a construção de um sistema moderno colonial de dominação do qual a educação é parte. Por suas relações de cumplicidade com a estrutura do saber, com a cultura do conhecimento acadêmico e com o sistema mundial moderno, a educação é relevante para o que se constitui como missão civilizadora moderno colonial. A conservação do sistema demanda um amplo e cambiante conjunto de estratégias de subalternização de diferentes grupos sociais. Há necessidade constante de reformulação das estratégias porque, com frequência, os grupos subalternizados não aceitam esse sistema, produzem formas diversas para a ele se oporem, nele introduzem mudanças, como parte de sua luta permanente por libertação. A luta (parte dos conhecimentos populares invalidados pelo projeto de educação hegemônico) cria condições para a tecelagem do pensamento liminar (idem).

O pensamento liminar não nega a existência da colonialidade e de suas produções, porém, instaura outra perspectiva para se olhar os processos que derivam da colonialidade: a fronteira, com a experiência da subalternidade. Essa proposição dá visibilidade ao local, que se expande além da dimensão geográfica e se produz como questão histórica, política e epistemológica, onde se produzem formas subalternas de pensar. As experiências subalternas constituem formas outras de racionalidade, com a articulação do que foi negado pela razão moderna e redimensionamento das relações entre lugar de teorização, lócus de enunciação e sujeito que conhece. A posição fronteiriça reinscreve o potencial epistemológico do sujeito subalterno que toma a razão subalterna como proposta crítica comprometida com a transformação das relações de subalternidade.

\footnotetext{
${ }^{10}$ De acordo com a lógica hegemônica, o fracasso resulta dos desempenhos individuais inapropriados. Predomina a explicação do fracasso escolar como o fracasso dos sujeitos que frequentam a escola, sem questionar o projeto de escola em curso, como nos mostram autores como Arroyo (2011) e Garcia (1996).
} 
A razão subalterna permite a articulação entre projetos educacionais e a descolonização do conhecimento por viabilizar o diálogo entre a educação e os processos sociais de libertação. Para consolidar essa proposição, Mignolo (2003) recorre à Pedagogia do Oprimido (FREIRE, 2006) por entendê-la potente na reflexão sobre o pensamento liminar, em especial pelos seguintes aspectos: a) o pensamento dialógico freireano como proposta contrahegemônica nas esferas da reflexão e da ação; b) o diálogo como ação e libertação da opressão, envolvendo as dimensões social, econômica, epistemológica, para além de sua capacidade de análise; c) sua relevância para os processos de descolonização intelectual, necessária à ruptura com os processos de subalternização em direção à libertação

A pedagogia se reinscreve na dinâmica social por sua potência de transformação e se fortalece a percepção da escola como espaço relevante na formulação de projetos educacionais contrahegemônicos, comprometidos com as classes populares. Vista desde as experiências subalternas, a escola expõe com mais intensidade suas tensões e seus percurso, por vezes invisíveis e silenciosos, de confronto com práticas antidemocráticas e antidialógicas e de produção de processos outros. Portanto, para conhecer a escola é preciso ir além das evidências e encontrar processos, atos e relações que não podem ser imediatamente perceptíveis por se contraporem ao modelo dominante. Neste sentido, foi fundamental ter o paradigma indiciário como um dos fios articuladores do nosso processo de pesquisa com as escolas públicas.

Para encontrar os diversos movimentos que constituem as experiências escolares e compreendê-los era indispensável o diálogo. Partir de uma epistemologia diferente da que criticamos permitiu a instauração de outros modos de relação com os sujeitos na escola. $\mathrm{O}$ deslocamento dos conceitos hegemônicos possibilitado pelo pensamento dialógico cria condições para a transformação da cultura do silêncio (FREIRE, 2006), que ofusca a situação de opressão e as condições para sua instauração. A crítica à subalternização e a aproximação entre os sujeitos permitem a percepção da libertação como uma possibilidade concreta.

Essa compreensão afirma como possíveis outros enquadramentos além dos hegemônicos, tanto do ponto de vista das formulações teóricas quanto das práticas escolares cotidianas. A escola, especialmente a pública, onde estão os/as estudantes das classes populares, em seus movimentos cotidianos se entretece à presença de diferentes culturas e à potência do pensamento subalterno. O cotidiano escolar é espaçotempo complexo de tensão, de produção de conhecimentos e de luta.

Em que pesem os parâmetros, instrumentos e escalas uniformes, o cotidiano da sala de aula afirma a todo momento a impossibilidade de enquadramento das crianças, seus processos e seus conhecimentos, como apuramos em todo o desenvolvimento da nossa pesquisa. Para além do que se pode capturar nos exames, a relação aprendizagemensino é plena de desafios que requerem concepções mais amplas da própria avaliação.

\section{DA FRONTEIRA SE VÊ O INVISÍVEL ${ }^{11}$}

A recomposição do processo de avaliação para conectá-lo à educação como prática da liberdade (FREIRE, 1978) requer um retorno ao debate sobre as relações que estabelece com a diferença, questionando a demarcação de identidades fixas que permite abordá-la num registro

\footnotetext{
11 Aqui, fronteira se encontra com a noção como proposta por Bhabha (1989), que a elabora como espaço de enunciação de vozes e histórias em dissonância com o discurso eurocêntrico, interrompendo a atuação do presente $\mathrm{e}$ anunciando a presença do novo como ato insurgente.
} 
hierárquico ${ }^{12}$. A sala de aula, espaço primeiro da avaliação escolar, é um contexto marcado pela diferença de processos de aprendizagem, percursos escolares e de vida, criando diferentes expectativas, perspectivas, projetos, intencionalidades, desafios, interesses, etc, não sendo possível estabelecer um limite claro e objetivo entre eles. Sem atenção aos modos de incorporação da diferença às práticas cotidianas, a crítica à avaliação classificatória, como procedimento excludente, pode se esvaziar por meio de práticas que distribuem estudantes diferentes por lugares desiguais, se utilizando de procedimentos nem sempre percebidos como discriminatórios.

A diferença precisa ser afirmada em suas dimensões histórica, cultural e social, como composição fluida, transitória, para não ser transfigurada em característica individual, tantas vezes confundida com característica inata. Tampouco pode ser entendida como ignorância, insuficiência, problema, distorção, deficiência: algo que precisa ser negado e superado. Outra percepção a ser evitada, por simplificá-la e conduzir a uma análise redutora, é a que confina a diferença ao desenvolvimento cognitivo, mantendo como referência, ainda que superficial, perspectivas universalizantes, que se evidenciam, por exemplo, na expressão por nós tantas vezes ouvida e lida: os sujeitos apresentam diferentes ritmos de aprendizagem.

Frequentemente, essas percepções estão atravessadas pela ideia de que há algo a ser corrigido. Assim, diferença e erro se aproximam. Por um lado, pelo matiz negativo que muitas vezes os atravessa, por não condizerem com os parâmetros fixos e os procedimentos padronizados reconhecidos como índices de qualidade. Por outro, pelos desafios e pelas possibilidades de criação de que são portadores. Em ambos os casos, sinalizam os limites da avaliação voltada à mensuração de desempenho e classificação hierárquica dos sujeitos.

O erro, questão recorrente ao se tratar da avaliação no cotidiano escolar, ocupa lugar relevante na elaboração das ideias sobre avaliação assumidas na pesquisa. Há muito, a pergunta o que sabe quem erra (ESTEBAN, 2001) ganha sentido pelo entendimento de que as respostas distintas das esperadas trazem conhecimentos, formas de conhecer e modos de expressão válidos, mesmo sem corresponder ao esperado. Portanto, o que denominamos como erros são, para além de respostas fora do padrão, indícios de modos outros de pensar, de compreender, de relacionar e de elaborar, bem como convite a ir além do já conhecido. O erro expressa a dimensão criativa da aprendizagem e talvez possa ser um dos caminhos a nos conectar com a razão subalterna.

Diante do erro, bem como do que se percebe como diferença, o movimento que na pesquisa se mostrou mais interessante é o dialógico e reflexivo, pois a compreensão do que assim se configura só se faz possível no encontro com o outro. O erro é uma questão da pedagogia e da avaliação, mas também interpelação à pedagogia e à avaliação por trazer para a centralidade do debate a problematização e a diferença.

Díaz Barriga (2012, p. 151, 152) faz a instigante proposta de uma Pedagogia do Erro:

Una pedagogía del error es una pedagogía de la reflexión. Implica adoptar en el acto educativo una perspectiva en que se asume la tarea docente como una actividad pausada, como un trabajo de largo aliento [...], un trabajo detallado, minucioso, en el cual el profesor puede analizar los pormenores del proceso de aprendizaje de cada estudiante.

\footnotetext{
12 Segue a aproximação com as proposições de Bhabha (1989, p. 22), com referência em sua noção de hibridismo cultural: "Essa passagem intersticial entre identificações fixas abre a possibilidade de um hibridismo cultural que acolhe a diferença sem uma hierarquia suposta ou imposta".
} 
Portanto, o erro não desqualifica o/a estudante ou seu processo de aprendizagem, do mesmo modo que a diferença não sustenta nem justifica a desigualdade; ambos validam, como elemento do trabalho pedagógico, os trajetos realizados pelos alunos e alunas, seus conhecimentos, seus desconhecimentos, suas experiências e suas culturas. Ambos requerem o diálogo.

Assim, a avaliação que tem sentido é a que indaga as práticas instauradas e as conclusões elaboradas para nos conectar aos processos de aprendizagemensino. Como não há padrão capaz de determiná-los, as práticas pedagógicas sempre nos colocam em espaços fronteiriços (liminares?) onde conhecimentos e desconhecimentos dialogam, o que tem nos levado ao encontro da avaliação como prática de investigação (ESTEBAN, 2001).

Nos cotidianos escolares com os quais vimos pesquisando, a avaliação que se anuncia como significativa não se trata de um instrumento do ensino, para acompanhamento e/ou verificação da aprendizagem, ou mensuração do desempenho estudantil, pelo/a professor/a. Não é um procedimento de controle dos resultados a alcançar (metas, objetivos, competências), de regulação dos percursos necessários para que o resultado previsto seja atingido ou de classificação hierárquica das crianças e de seus conhecimentos e processos.

A avaliação se associa à pedagogia que busca a permanente ampliação dos conhecimentos; é um exercício dialógico, crítico, reflexivo e participativo que fomenta a problematização de resultados produzidos, percursos vividos e aprendizagens que os atravessam, indicando também os limites percebidos, os conhecimentos que se fazem necessários e que mobilizam a continuidade do movimento aprendizagemensino. Como processo dialógico, não pode se realizar sobre o outro, somente ganha sentido com o outro e se conecta à experiência humana de sua incompletude (FREIRE, 2006). Nesta acepção, os limites, as lacunas, os desconhecimentos, enfim, os erros, indicam desafios e trazem outros elementos à tecelagem coletiva de conhecimentos, que convoca sempre a novas aprendizagens, enquanto expõe os desconhecimentos, nutrindo também os processos individuais. Perspectiva próxima às propostas da avaliação para as aprendizagens (STOBART, 2010; FERNANDES, 2009), porém, demarca o sentido político da educação e a necessidade de ruptura com o projeto de escolarização e de avaliação hegemônico. Com este segundo movimento dialoga com a avaliação emancipatória (SAUL, 1991).

Evidencia-se a necessidade de ressaltar que o/a estudante não é o objeto da avaliação, mas um sujeito que colabora com o processo de avaliação do qual participa. O entendimento da trama avaliativa na perspectiva do pensamento liminar e sua condução pelo diálogo freireano nos impele a deixar de pensá-la como relação sujeito-objeto. Proposta como relação intersubjetiva, somente se afirma como processo democrático com a presença efetiva dos/as estudantes, crianças incluídas. A mudança epistemológica provoca uma releitura do encaminhamento teórico e formula um desafio metodológico: produzir práticas de avaliação que incorporem os/as estudantes nas diferentes etapas que esse processo requer ${ }^{13}$. Desafio ampliado quando as políticas públicas fomentam práticas avaliativas de caráter classificatório.

Se o projeto hegemônico de avaliação se consubstancia no exame, dando prioridade à técnica a fim de garantir sua objetividade e neutralidade (como visto, fundamentais à validação social de seu efeito classificatório e seletivo), a proposta elaborada num registro contra hegemônico

\footnotetext{
${ }^{13}$ Esta questão foi central no projeto de pesquisa recém concluído. Ainda que a participação estudantil seja formulada em propostas como avaliação para a aprendizagem (Stobart, 2010) ou avaliação emancipatória (Saul, 1991), nossa experiência docente e as pesquisas realizadas indicam o distanciamento de grande parte das práticas cotidianas dessas perspectivas de avaliação.
} 
encontra a ética como elemento articulador do processo de avaliação ${ }^{14}$. Sendo assim, ao falar de avaliação não estou falando de eficiência e eficácia, mas de complexidade, problematização e transformação. A avaliação se realiza no diálogo entre ensino e aprendizagem.

A pesquisa que desenvolvemos em parceria com professoras no cotidiano de escolas públicas nos ofereceu inúmeras pistas e evidências de que a inexistência de avaliações padronizadas, em suas modalidades escolar e em larga escala, abre maiores possibilidades de realização de aulas mais criativas e com mais oportunidades de partilha, com as crianças, de decisões sobre o trabalho pedagógico, incluindo a avaliação. Considerando as diversas realidades que encontramos, algumas características dos trabalhos que acompanhamos se conectam à percepção da diferença como potência que mobiliza encontros e aprendizagens, à problematização da perspectiva classificatória da avaliação e à compreensão da escola pública como espaço das classes populares que pode vincular-se à luta pela libertação.

Cito brevemente nossos achados: a) a articulação de momentos do trabalho pedagógico com experiências cotidianas que trazem para a sala de aula tanto as condições objetivas de vida e de estudo das crianças como as dimensões subjetivas que as atravessam, considerando a avaliação como necessária à produção de possibilidades de transformação do que se mostra insatisfatório, especialmente na escola; b) a elaboração de propostas pedagógicas envolvendo modos distintos de produção do conhecimento; c) a incorporação de lutas pela transformação das condições desiguais de vida como parte da ação escolar e como objeto de estudo e d) a preocupação crescente com a ação, tanto docente quanto discente, como processo reflexivo, crítico, solidário, autônomo, criativo, articulado em suas dimensões política, pedagógica, ética e estética.

Nossa experiência na pesquisa me permite afirmar que no cotidiano escolar vivenciam-se exercícios de avaliação com o outro, mesmo que em momentos específicos e à margem das práticas predominantes, em que se pretende conhecer os processos pedagógicos instaurados, apreciar seus resultados, interrogá-los e apresentar possibilidades e desafios para a continuidade do trabalho. O cotidiano mostra-se favorável ao processo compartilhado, coletivo, no qual, a interação sujeitosujeito é indispensável e insubstituível, embora muitas vezes em tensão com o projeto institucional para a educação, A avaliação, nesses momentos, se configura como instrumento de fortalecimento da autonomia docente, do lugar da criança, com suas experiências infantis, e dos movimentos de constante ampliação curricular. As ações escolares se vinculam ao processo de afirmação da alteridade, de compreensão do mundo e de produção de modos amorosos e vigorosos de intervenção neste mundo, sendo o conhecimento, em sua pluralidade, fundamental para movimentos que encontram em cada ponto de chegada elementos que mobilizam a outras aprendizagens.

As reflexões apresentadas neste texto são movidas pelas tensões e possibilidades vividas com a escola pública que cotidianamente se produz em seus (des)encontros com as classes populares. Nossa pesquisa pretendeu trilhar o caminho indicado por Freire (2006, p. 118): “[...] quanto mais investigo o pensar do povo com ele, tanto mais nos educamos juntos. Quanto mais nos educamos, tanto mais continuamos investigando".

${ }^{14}$ A prioridade da ética na avaliação é tratada por Díaz Barriga (1999). 


\section{REFERÊNCIAS}

AFONSO, Almerindo. Para discutir la hegemonía epistémica evaluativa eurocéntrica: un enfoque exploratorio. Revista de la Asociación de Sociología de la Educación, Valencia, v. 10, n. 2, p. 156 - 166, 2017.

APPLE, Michael. Cultural politics \& education. New York: Columbia University, Teachers College, 1996.

ARROYO, Miguel. O direito à formação humana como referente da avaliação. In: SORDI, Mara Regina Lemes; VARANI, Adriana; MENDES, Geisa do Socorro Cavalcanti Vaz (org.). Qualidade(s) da escola pública. Reinventando a avaliação como resistência. Uberlândia: Navegando, 2017.

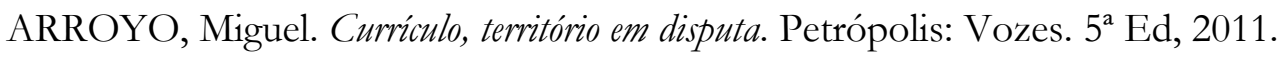

BHABHA, Homi. O local da cultura. Belo Horizonte: UFMG, 1989.

DÍAZ BARRIGA, Angel. Pensar la didáctica. Buenos Aires: Amorrortu, 2012.

DÍAZ BARRIGA, Angel. Uma polêmica em relação ao exame. In: ESTEBAN, Maria Teresa (org.). Avaliação: uma prática em busca de novos sentidos. Rio de Janeiro: DP\&A, 1999.

ESTEBAN, Maria Teresa. O que sabe quem erra? Reflexões sobre avaliação e fracasso escolar. Rio de Janeiro: DP\&A, 2001.

FOUCAULT, Michel. Vigiar e punir. Petrópolis: Vozes, 1999.

FRANCO, Maria Laura Barbosa. Pressupostos epistemológicos da avaliação educacional. Cadernos de Pesquisa, São Paulo, n. 74, p. 63- 67, ago, 1990.

FREIRE, Paulo. Pedagogia do Oprimido. São Paulo: Paz e Terra, 2006.

FREIRE, Paulo; FAUNDEZ, Antonio. Por uma pedagogia da pergunta. Rio de Janeiro: Paz e Terra, 1985.

FREITAS, Luiz Carlos. Os reformadores empresariais da educação: da desmoralização do magistério à destruição do sistema público de educação. Educação e Sociedade, Campinas, v.33, n. 119, p. 379-404, abr./jun, 2012.

FREITAS, Luiz Carlos. Eliminação adiada: o ocaso das classes populares no interior da escola e a ocultação da (má) qualidade do ensino. Educação e Sociedade, Campinas, v.28, n.100, p. 965-987, oct, 2007.

GARCIA, Regina Leite. Formação de professoras alfabetizadoras - reflexões sobre uma prática coletiva. In: GARCIA, Regina Leite (org.). Formação de professoras alfabetizadoras - reflexões sobre a prática. São Paulo: Cortez, 1996.

GIMENO SACRISTÁN, José. La Pedagogía por objetivos: obsesión por la eficiencia. Madrid: Morata, 1982.

GIROUX, Henry. A escola crítica e a política cultural. São Paulo: Cortez, 1987.

GUBA, Egon; LINCOLN, Yvonna. Fourth generation evaluation. California: Sage Publications, 1989. HOFFMANN, Jussara. O jogo do contrário em avaliação. Porto Alegre: Mediação, 2005.

HORTA NETO, João Luiz. Avaliações Educacionais e seus reflexos em ações federais e na Mídia Eletrônica. Estudos em Avaliação Educacional, São Paulo, v. 25, n. 59, p. 172-201, set./dez, 2014.

MIGNOLO, Walter. Histórias locais, projetos globais. Belo Horizonte: UFMG, 2003. 
SAUL, Ana Maria. Avaliação emancipatória. São Paulo: Cortez, 1991.

STOBART, Gordon. Tiempos de pruebas: los usos y abusos de la evaluación. Madrid: Morata. 2010.

TOMAZ, Sandra Cristina; SILVA, Margarida Montejano. O que as escolas fazem que os testes estandardizados desprezam na avaliação da qualidade? Ouvindo as escolas. IN: SORDI, Mara Regina Lemes; VARANI, Adriana; MENDES, Geisa do Socorro Cavalcanti Vaz (org.). Qualidade(s) da escola pública. Reinventando a avaliação como resistência. Uberlândia: Navegando, 2017.

VILLAS BOAS, Benigna Maria de Freitas; DIAS, Elisângela Teixeira Gomes. Provinha Brasil e avaliação formativa: um diálogo possível?. Educar em Revista, Curitiba n. spe 1, p. 35-53, 2015.

ZEICHNER, Kenneth. Formando professores reflexivos para uma educação centrada no aprendiz: possibilidades e contradições. In: ESTEBAN, Maria Teresa; ZACCUR, Edwiges (org.). Professora-pesquisadora - uma práxis em construção. Rio de Janeiro: DP\&A, 2002.

Submetido em julho de 2020 Aprovado em setembro de 2020

\section{Informações do(a)(s) autor(a)(es)}

Maria Teresa Esteban

Professora da Faculdade de Educação e do Programa de Pós-Graduação em Educação da Universidade Federal Fluminense

E-mail:mtesteban@uol.com.br

ORCID: https://orcid.org/0000-0003-0130-149X

Link Lattes: http://lattes.cnpq.br/9777735988809472

Bruna de Souza Fabricante Pina

Professora do Ensino Básico, Técnico e Tecnológico do Departamento dos Anos Iniciais do Ensino Fundamental do Colégio Pedro II

E-mail: brunadesouzafabri@gmail.com

ORCID: https://orcid.org/0000-0003-2617-8862

Link Lattes: http://lattes.cnpq.br/1042166126318375 